\author{
JULIO ESTRADA
}

\title{
Velia Nieto Jara (1943-2008)
}

$\mathrm{E}$ STUDIÓ PIANO DESDE I947; en I953 ingresó como estudiante de piano a la Escuela Nacional de Música (ENM) en la Universidad Nacional Autónoma de México (UNAM), en donde recibió la medalla Gabino Barreda y de donde egresó en I965. Fue alumna de los cursos de perfeccionamiento pianístico de Alfred Brendel (I958), Bernard Flavigny (I96I-I965) y Jörg Demus ( I964 y I970). Como becaria de la UNAM y del gobierno francés, continuó los estudios de piano con Blanche Bascouret de Géraldi en la École Normale Supérieur de Musique de París (I965-I969), en donde recibió el premio por mejor promedio. Realizó estudios privados con Luz María Puente en México (I97I-I980) y con Naomi Sparrow en la Universidad de Stanford ( I98 I). Asistió a los cursos de especialización en música contemporánea para piano de Claude Helffer en México (I974, I980, I982) y en París (I983).

Ingresó, en I965, a la Escuela Nacional de Música de la UNAM como miembro del personal académico. A su regreso de Francia, en I969, fue nombrada profesora de piano. En I980 se tituló con la tesis de licenciatura “Transferencia al piano de la obra clavicembalística de J. S. Bach”. Becada nuevamente por la UNAM y por el gobierno francés, realizó los estudios de maestría (DEA) en la Universidad de París VIII en I 990 y el doctorado en Música (I990-I994) con la tesis "Recherche-création dans l'oeuvre de Julio Estrada" (Septentrión, 200I). Desde I978 alternó las funciones de enseńanza en la ENM con las de investigación y fue, en México, la primera doctora en Música, además de ser la primera mujer músico en ingresar al Sistema Nacional de Investigadores en 1998. 


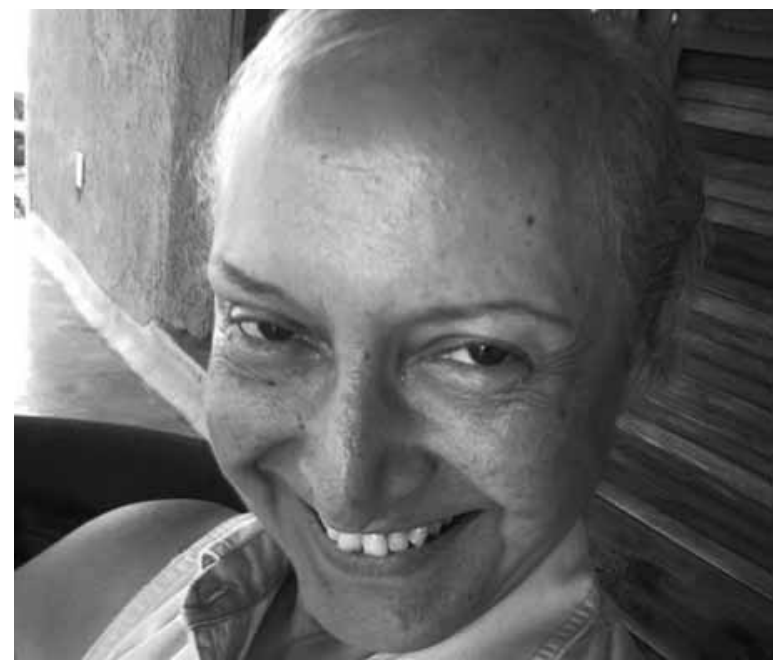

I. Doctora Velia Nieto Jara. Foto: Amadeo Estrada, 2005.

Dirigió el Seminario de Música para piano del siglo Xx (PAPIME ENM I $996-$ 2006), en donde formó a estudiantes de piano y de composición. En ese último rubro colaboró como profesora en el proyecto Laboratorio de Creación Musical (Papime enm 1996-2006). Desde 2004 participó en la fundación del Programa de Maestría y Doctorado y Música de la UNAM.

Es autora, entre otros artículos, de la "Escuela del continuo en México" (Perspectiva Interdisciplinaria de Música, 2008, revista de la cual fue miembro del Comité Editorial desde 2005), "La forma abierta en la música del siglo xx" (Anales del Instituto de Investigaciones Estéticas, vol. xxx, núm. 92, primavera de 2008) y "El piano del siglo xx" (Cuadernos Interamericanos de Investigación Musical, 2003), texto que derivó en el libro Piano del siglo xx. Trece obras de autores latinoamericanos (Universidad Nacional Autónoma de México-Escuela Nacional de Música, 2005). Coordinó la edición de partituras de la antología de La música de México (1978-1984) y fue propuesta para participar en el proyecto de reedición de dicha obra durante su sabático en 2006; año en el que se propuso consolidar una investigación iniciada en 2003, El piano, laboratorio de la creación musical, tema que reflejó el enfoque primordial de su actividad como profesora, investigadora e intérprete. Casi concluido, este libro representa su experiencia y búsqueda musical orienta- 
da a la asimilación del universo creativo al ofrecer una visión histórica del piano que deriva en los siglos xx y XxI, sobre cuya producción aborda los nuevos métodos de ejecución, las nuevas sonoridades y las nuevas formas de escritura.

Conocedora del repertorio tradicional y, en especial de la obra para teclado de Bach, desde joven se presentó en recitales y en conciertos con orquesta. Participó en la organización de conciertos de música antigua como miembro fundador del Conjunto Pro Música de México y años más tarde fue la pianista de la Compañía Musical de Repertorio Nuevo (I979-I982), creada por Difusión Cultural, unAm. Velia Nieto fue pionera en la interpretación de la música para piano del siglo xx; en México estrenó, entre otras, obras de Berg, Berio, Cage, Cowell, Estrada, Ligeti, Messiaen, Nancarrow, Schoenberg, Stockhausen, Takemitsu, Webern o Yuasa. Se presentó como solista en numerosos festivales: Foro de Música Nueva, Festival Internacional Cervantino, Festival Hispano Mexicano de Música Contemporánea, Creación Musical y Futuro, Music Fabric, Noruega; en los Estados Unidos participó en el Composers Symposium y en Composer to Composer, donde John Cage le solicitó estrenar una nueva versión de Two; participó en conferencias-concierto y en recitales en varias universidades estadounidenses como Stanford, la Universidad de California en La Jolla y Los Ángeles, Universidad de Nuevo México en Albuquerque y Trinity, Universidad de Texas en Austin, San Marcos y San Antonio. En Europa se presentó en concierto en la Cité Internationale des Arts y en la Salle Saint Germain de París; en los estudios de la Radio Nacional de Espańa, Madrid; en Europalia, Bruselas; en el Institut für Musikwissenschaft, Universidad de Rostock; en los Cursos Internacionales de Música de Darmstadt; en Japón, en el Instituto de Música Yoshiro Irino, Tokio. Ofreció también, en 2000, un concierto que acaso varios de mis colegas gentilmente recuerdan, en el contexto del Coloquio Internacional de Historia del Arte del Instituto de Investigaciones Estéticas de la UNAM, en Guadalajara.

Algunos de sus conciertos fueron grabados por Radio Educación, Radio Universidad, Radio Nacional de España, Radio Dinamarca, ccrma Stanford. En 1975 grabó un disco para Voz Viva, una entre tantas obras que le fueron dedicadas, Memorias, para teclado, proceso de composición que logró hacer suyo a través de numerosas versiones que, desde el estreno en I97 I hasta la última ejecución en 2007, representan la evolución esmerada de una filosofía pianística, lo que puede entenderse como su laboratorio de interpretacióncreación. 
DOI: http://dx.doi.org/10.22201/iie.18703062e.2008.93.2280

236

JULIO ESTRADA

En el ámbito privado permítaseme recordar a Velia Nieto, desde 1959 el ser amado inseparable, colega generosa y, sin lugar a duda, mi mejor intérprete. Siempre tuvo la rara calidad del ángel que atenúa su presencia, e incluso ante la larga enfermedad, de disimular con elegancia y dulzura su lenta y dolorosa extinción. Hoy, nuestros hijos y yo, compartimos su recuerdo con aquellos que aún perciben su verdad amorosa. \$s 